\title{
DIGITALCOMMONS
}

\section{Extension of Grizzle’s Classic Crossover Design}

James F. Reed III

Christiana Care Hospital System, Newark, Delaware, JFReed3rd@gmail.com

Follow this and additional works at: http://digitalcommons.wayne.edu/jmasm

Part of the Applied Statistics Commons, Social and Behavioral Sciences Commons, and the Statistical Theory Commons

\section{Recommended Citation}

Reed, James F. III (2011) "Extension of Grizzle’s Classic Crossover Design," Journal of Modern Applied Statistical Methods: Vol. 10 : Iss. 1 , Article 29.

DOI: $10.22237 /$ jmasm/1304224080

Available at: http://digitalcommons.wayne.edu/jmasm/vol10/iss1/29

This Regular Article is brought to you for free and open access by the Open Access Journals at DigitalCommons@WayneState. It has been accepted for inclusion in Journal of Modern Applied Statistical Methods by an authorized editor of DigitalCommons@WayneState. 


\title{
Extension of Grizzle's Classic Crossover Design
}

\author{
James F. Reed III \\ Christiana Care Hospital System, \\ Newark, Delaware
}

The crossover design compares treatments $\mathrm{A}$ and $\mathrm{B}$ over two periods using sequences $\mathrm{AB}$ and $\mathrm{BA}$ (the $\mathrm{AB} \mid \mathrm{BA}$ design) and is the classic design most often illustrated and critiqued in textbooks. Other crossover designs have been used but their use is relatively rare and not always well understood. This article introduces alternatives to a randomized two-treatment, two-period crossover study design. One strategy, which is to extend the classic $\mathrm{AB} \mid \mathrm{BA}$ by adding a third period to repeat one of the two treatments, has several attractive advantages; an added treatment period may not imply a large additional cost but will allow carryover effects to be estimated and compared with the within-subject variability. Careful choice of treatment sequences will enable the first two trial periods to constitute a conventional two-period crossover trial if the third treatment period leads to excessive subject drop-outs. Four alternative designs that address the first-order carryover effect are presented. These designs have more statistical power than the classic design and allow the treatment effects to be estimated, even in the presence of a carryover effect.

Key words: Crossover design, Grizzle, carryover effect.

\section{Introduction}

A crossover study is a longitudinal study in which subjects receive a sequence of different treatments; these designs are common in many scientific disciplines. In $\mathrm{AB} \mid \mathrm{BA}$ crossover studies, subjects are randomly assigned to receive either treatment $A$ in the first treatment period followed by treatment $B$ in the second period or treatment $B$ in the first period followed by treatment $\mathrm{A}$ in the second period. The crossover study allows for a within-subject comparison between treatments because each subject serves as his or her own control, the inter-patient variability is removed from the comparison between treatments and it can provide unbiased estimates for the differences between treatments. However, frequent misapplications of the design in clinical trials and even more frequent misanalysis of the data

James F. Reed III, Ph.D., is a Senior Biostatistician. Email him at: JFReed3rd@gmail.com. have nearly doomed the crossover trial in clinical research (Freeman, 1989; Senn, 1994; Senn, 1996).

The most damning characteristic of a crossover study is the potential of a carryover effect of one treatment to the next period. To address this issue, researchers typically include washout periods in their study designs. These washout periods are thought to be of sufficient length to negate any lingering effect of one treatment into the next period. Unfortunately, what a sufficiently long washout period might be remains unclear. In this article, and in most of the literature on crossover designs, the persistence of a carryover effect is assumed to last for only a single period (a first-order carryover effect) and it is also assumed that the carryover effect is different for different treatments. If a carryover effect is suspected in any crossover trial, then a term for this effect must be included in the model and accounted for in the subsequent analysis. This article introduces three simple alternatives to Grizzle's classic $\mathrm{AB} \mid \mathrm{BA}$ crossover design. These designs have more statistical power than the $A B \mid B A$ design and allow unbiased treatment effects to 
be estimated, even when a simple-order carryover effect is specified.

\section{The Traditional Crossover Model with} Continuous Data

The traditional design model assumes that each treatment has a simple first-order carryover effect that does not interact with the direct effect of the treatment in the subsequent period and that subject effects are either fixed or random. Although a variety of models are considered in the literature, virtually all of the work in crossover designs has the following traditional statistical model which assumes the following for the response of patient $\mathrm{y}_{\mathrm{ij}}$.

If $y_{\mathrm{ijk}}$ denotes the observed response of subject $j(j=1, \ldots, n)$ in period $i(i=1, \ldots, p)$, then

$$
\mathrm{y}_{\mathrm{ij}}=\mu+\pi_{\mathrm{i}}+\tau_{\mathrm{d}(\mathrm{i}, \mathrm{j})}+\lambda_{\mathrm{d}(\mathrm{i}-1, \mathrm{j})}+\beta_{\mathrm{j}}+\varepsilon_{\mathrm{ij}} .
$$

where $\pi_{\mathrm{i}}$ is the effect of period $\mathrm{i} ; \tau_{\mathrm{d}(\mathrm{i}, \mathrm{j})}$ is the direct effect of treatment $\mathrm{D}, \lambda_{\mathrm{d}(\mathrm{i}-1, \mathrm{j})}$ is the simple first-order carryover effect of treatment $D$ and $\mathrm{d}(\mathrm{i}, \mathrm{j})$ is the treatment allocated to patient $\mathrm{j}$ in period $\mathrm{i}, \lambda_{\mathrm{d}(0, \mathrm{j})}=0$ for all $\mathrm{j}$. It is assumed that all these effects are fixed effects. $\beta_{j}$ is the effect of patient $\mathrm{j}$ and $\varepsilon_{\mathrm{ij}}$ is the error term. The random subject effect, $\beta_{\mathrm{j}}$, and the experimental error, $\varepsilon_{\mathrm{ij}}$, are assumed to be mutually independently distributed as $\mathrm{N}\left(0, \sigma_{\beta}^{2}\right)$ and $\mathrm{N}\left(0, \sigma_{\varepsilon}^{2}\right)$.

\section{The Classic AB|BA}

The crossover design that compares treatments $\mathrm{A}$ and $\mathrm{B}$ over two periods using sequences $\mathrm{AB}$ and $\mathrm{BA}$ (the $\mathrm{AB} \mid \mathrm{BA}$ design) is the classic design and is most often illustrated and critiqued in textbooks (Grizzle, 1965). Other crossover designs have been utilized but their use is relatively rare and is not always well understood. For example, when more than two treatments are to be compared, an extensive use of each subject may be desirable when the number of periods can be extended.

The primary purpose of an $\mathrm{AB} \mid \mathrm{BA}$ crossover trail is to estimate the treatment contrast $\tau_{\mathrm{A}^{-}} \tau_{\mathrm{B}}$ (see Table 1$)$. The period effects $\pi_{1}$ and $\pi_{2}$, the first-order carryover effects $\lambda_{\mathrm{A}}$ and $\lambda_{\mathrm{B}}$, and $\mu$ are typically regarded as nuisance parameters that should be eliminated from any estimate. In sequence $\mathrm{AB}$, the contrast $\mathrm{c}_{1}, \mathrm{y}_{11}$ $\mathrm{y}_{21}$, has the expected value of $\mathrm{E}\left[\mathrm{c}_{1}\right]=\mathrm{E}\left[\mathrm{y}_{11}-\mathrm{y}_{21}\right]$ $=\left(\pi_{1}-\pi_{2}\right)+\left(\tau_{\mathrm{A}}-\tau_{\mathrm{B}}\right)-\lambda_{\mathrm{A}}$, while in sequence $\mathrm{BA}$, the contrast $\mathrm{c}_{2}, \mathrm{y}_{21}-\mathrm{y}_{22}$, has the expected value of $\mathrm{E}\left[\mathrm{c}_{2}\right]=\mathrm{E}\left[\mathrm{y}_{21}-\mathrm{y}_{22}\right]=\left(\pi_{1}-\pi_{2}\right)-\left(\tau_{\mathrm{A}}-\right.$ $\left.\tau_{\mathrm{B}}\right)-\lambda_{\mathrm{B}}$.

The difference between contrasts $c_{1}$ and $c_{2}$ may be expressed is $2\left(\tau_{A}-\tau_{B}\right)-\left(\lambda_{A}-\lambda_{B}\right)$. It is then possible to generate a hypothesis by forming the differences in the two contrasts between responses for the two periods. That difference for the respective patients may be expressed by $\mathrm{H}_{\mathrm{CROS}}:\left\{2\left(\tau_{\mathrm{A}}-\tau_{\mathrm{B}}\right)-\left(\lambda_{\mathrm{A}}-\lambda_{\mathrm{B}}\right)=0\right\}$. $\mathrm{H}_{\mathrm{CROS}}$ is a combined null hypothesis tested by the difference (or crossover) test of equality of both the treatment effects and carryover effects of $\mathrm{A}$ and $\mathrm{B}\left\{\tau_{\mathrm{A}}=\tau_{\mathrm{B}}, \lambda_{\mathrm{A}}=\lambda_{\mathrm{B}}\right\}$. The treatment effect and carryover effect are said to be aliased. The rejection of $\mathrm{H}_{\mathrm{CROS}}$ is interpreted as demonstrating that the direct and/or carryover effects of A and B are different in the sense of a prevailing larger response for one treatment than the other across the two periods.

In sequence $\mathrm{AB}$, the contrast $\mathrm{c}_{3}, \mathrm{y}_{11}+$ $\mathrm{y}_{21}$, has the expected value of $\mathrm{E}\left[\mathrm{c}_{3}\right]=\mathrm{E}\left[\mathrm{y}_{11}+\mathrm{y}_{21}\right]$ $=2 \mu+\left(\pi_{1}+\pi_{2}\right)+\left(\tau_{\mathrm{A}}+\tau_{\mathrm{B}}\right)+\lambda_{\mathrm{A}}$, and in sequence $\mathrm{BA}$, the contrast $\mathrm{c}_{4}, \mathrm{y}_{21}+\mathrm{y}_{22}$, has the expected value of $\mathrm{E}\left[\mathrm{c}_{4}\right]=\mathrm{E}\left[\mathrm{y}_{21}+\mathrm{y}_{22}\right]=2 \mu+\left(\pi_{1}\right.$ $\left.+\pi_{2}\right)+\left(\tau_{\mathrm{A}}+\tau_{\mathrm{B}}\right)+\lambda_{\mathrm{B}}$. The difference between $c_{3}$ and $c_{4}$ differ by $\lambda_{A}-\lambda_{B}$, and is a measure of the net carryover effect.

The hypothesis, $\mathrm{H}_{\mathrm{SEQ}}: \lambda_{\mathrm{A}}=\lambda_{\mathrm{B}}$, has been proposed for use when deciding whether the rejection of the hypothesis $\mathrm{H}_{\mathrm{CROS}}$ is due mainly to differences between the direct treatment effects $\tau_{\mathrm{A}}=\tau_{\mathrm{B}}$ or between the carryover effects $\lambda_{\mathrm{A}}=\lambda_{\mathrm{B}}$. A non-significant $\mathrm{H}_{\mathrm{SEQ}}$ supports the contention that there is a difference between $\tau_{\mathrm{A}}$ and $\tau_{\mathrm{B}}$ as the primary contradiction of $\mathrm{H}_{\mathrm{CROS}}$. Alternatively, a significant $\mathrm{H}_{\mathrm{SEQ}}$ is interpreted as indicating that the differences between $\lambda_{A}$ and $\lambda_{\mathrm{B}}$ may account for the contradiction of $\mathrm{H}_{\mathrm{CROS}}$. When assessing the SEQ hypothesis, the type II error (falsely failing to reject the null hypothesis of no first-order carryover effect) is of some concern.

To reduce the probability of making a type II error, the recommendation has been to use larger than the usual $\alpha$, such as $25 \%$. In bioequivalence studies, the commonly used significance level in a bioequivalence study for 


\section{EXTENSION OF GRIZZLE'S CLASSIC CROSSOVER DESIGN}

Table 1: Design AB|BA

\begin{tabular}{|c|c|c|}
\hline AB|BA Design & $\begin{array}{c}\text { Period } 1 \\
(\mathrm{k}=1)\end{array}$ & $\begin{array}{c}\text { Period } 2 \\
(\mathrm{k}=2)\end{array}$ \\
\hline Sequence $\mathrm{AB}(\mathrm{i}=1)$ & $\mu+\pi_{1}+\tau_{\mathrm{A}}$ & $\mu+\pi_{2}+\tau_{\mathrm{B}}+\lambda_{\mathrm{A}}$ \\
\hline Sequence BA (i $=2)$ & $\mu+\pi_{1}+\tau_{\mathrm{B}}$ & $\mu+\pi_{2}+\tau_{\mathrm{A}}+\lambda_{\mathrm{B}}$ \\
\hline
\end{tabular}

Table 1 Notes:

Sequence $\mathrm{AB}(\mathrm{i}=1): \mathrm{E}\left(\mathrm{y}_{\mathrm{AB}, 1}\right)=\mu_{\mathrm{AB}, 1}=\mu+\pi_{1}+\tau_{\mathrm{A}}, \mathrm{E}\left(\mathrm{y}_{\mathrm{AB}, 2}\right)=\mu_{\mathrm{AB}, 2}=\mu+\pi_{2}+\tau_{\mathrm{B}}+\lambda_{\mathrm{A}}$

Sequence BA $(\mathrm{i}=2)$ : $\mathrm{E}\left(\mathrm{y}_{\mathrm{BA}, 1}\right)=\mu_{\mathrm{BA}, 1}=\mu+\pi_{1}+\tau_{\mathrm{B}}, \mathrm{E}\left(\mathrm{y}_{\mathrm{AB}, 2}\right)=\mu_{\mathrm{BA}, 2}=\mu+\pi_{2}+\tau_{\mathrm{A}}+\lambda_{\mathrm{B}}$

In sequence $A B$, the contrast $c_{1}$ has the expected value of $E\left[c_{1}\right]=E\left[y_{11}-y_{21}\right]=\left(\pi_{1}-\pi_{2}\right)+\left(\tau_{A}-\tau_{B}\right)-\lambda_{A}$

In sequence $B A$, the contrast $c_{2}$ has the expected value of $E\left[c_{2}\right]=E\left[y_{21}-y_{22}\right]=\left(\pi_{1}-\pi_{2}\right)-\left(\tau_{A}-\tau_{B}\right)-\lambda_{B}$

In sequence $A B$, the contrast $c_{3}$ has the expected value of $E\left[c_{3}\right]=E\left[y_{11}+y_{21}\right]=$ $2 \mu+\left(\pi_{1}+\pi_{2}\right)+\left(\tau_{\mathrm{A}}+\tau_{\mathrm{B}}\right)+\lambda_{\mathrm{A}}$

In sequence $\mathrm{BA}$, the contrast $\mathrm{c}_{4}$ has the expected value of $\mathrm{E}\left[\mathrm{c}_{4}\right]=\mathrm{E}\left[\mathrm{y}_{21}+\mathrm{y}_{22}\right]=$ $2 \mu+\left(\pi_{1}+\pi_{2}\right)+\left(\tau_{\mathrm{A}}+\tau_{\mathrm{B}}\right)+\lambda_{\mathrm{B}}$

SEQ is $25 \%$ (Chen \& Tsong, 2007). This recommendation may be followed for any analyses.

A third hypothesis compares the two sequences with respect to the responses for the first period only. The prevailing strategy is to use this test if a significant carryover effect is identified. This test procedure is referred to as PAR. When data from the second period are ignored, an $\mathrm{AB} / \mathrm{BA}$ crossover design has the same structure as a PARallel group trial. PAR addresses the hypothesis of equality of direct treatment effects of $\mathrm{A}$ and $\mathrm{B}$ in the presence of unequal carryover effects (Freeman, 1986; Willan \& Pater, 1986). An unbiased estimator of the treatment effect can be found by means of a t-test applied to the measurements obtained in the first period only; however, unfortunately, when using data from the first period only, advantages of the crossover design are negated.

\section{Balaam's Design}

To solve the first-order crossover problem inherent in the traditional $\mathrm{AB} \mid \mathrm{BA}$ design, an extension of the Grizzle design is needed. One alternative involves the use of additional treatment sequences in the two periods. For example, $\mathrm{AA}|\mathrm{AB}| \mathrm{BA} \mid \mathrm{BB}$ (Balaam, 1968) could be utilized. This design is universally optimal for estimating treatment effects regardless of whether baseline observations are available, and it is far more efficient than the classic AB|BA (Laska, Meisner \& Kushner, 1983). However, in the absence of any carryover effect, this design is inefficient because many of the subjects will contribute little - if any - information to the estimate of treatment differences in the AA and BB sequences.

The schematic for this design is shown in Table 2. In sequence $\mathrm{AB}$, the contrast, $\mathrm{c}_{1}=$ $\left(\mathrm{y}_{11}-\mathrm{y}_{12}\right)$, has an expected value of $\mathrm{E}\left[\mathrm{c}_{1}\right]=\mathrm{E}\left[\mathrm{y}_{11}\right.$ $\left.-\mathrm{y}_{12}\right]=\left(\pi_{1}-\pi_{2}\right)+\left(\tau_{\mathrm{A}}-\tau_{\mathrm{B}}\right)-\lambda_{\mathrm{A}}$, in sequence $\mathrm{BA}$, the contrast $\mathrm{c}_{2}=\left(\mathrm{y}_{21}-\mathrm{y}_{22}\right)$, has expected value of $\mathrm{E}\left[\mathrm{c}_{2}\right]=\mathrm{E}\left[\mathrm{y}_{21}-\mathrm{y}_{22}\right]=\left(\pi_{1}-\pi_{2}\right)-\left(\tau_{\mathrm{A}}-\tau_{\mathrm{B}}\right)$ - $\lambda_{\mathrm{B}}$, in sequence AA, the contrast $c_{3}$ has an expected value of $E\left[c_{3}\right]=E\left[y_{31}-y_{32}\right]=\left(\pi_{1}-\pi_{2}\right)$ $-\lambda_{\mathrm{A}}$, and in sequence $\mathrm{BB}$, the contrast $\mathrm{c}_{4}$ has an expected value of $E\left[c_{4}\right]=E\left[y_{41}-y_{42}\right]=\left(\pi_{1}-\pi_{2}\right)$ - $\lambda_{\mathrm{B}}$. A linear combination of $\mathrm{c}_{1}-\mathrm{c}_{2}-\mathrm{c}_{3}+\mathrm{c}_{4}$ yields an unbiased estimate of the treatment differences.

To derive an unbiased estimate of carryover effects, $c_{5}$ is defined in sequence $A B$ as $\mathrm{y}_{11}+\mathrm{y}_{21}$. The expected value of $\mathrm{c}_{5}$ is then $\mathrm{E}\left[\mathrm{c}_{5}\right]=\mathrm{E}\left[\mathrm{y}_{11}+\mathrm{y}_{21}\right]=2 \mu+\left(\pi_{1}+\pi_{2}\right)+\left(\tau_{\mathrm{A}}+\tau_{\mathrm{B}}\right)$ $+\lambda_{\mathrm{A}}$. In sequence $\mathrm{BA}, \mathrm{c}_{6}$ is defined as $\mathrm{y}_{21}+\mathrm{y}_{22}$ 
Table 2: Balaam's Design (AB|BA|AA|BB)

\begin{tabular}{|c|c|c|}
\hline AB $\mid$ BA Design & $\begin{array}{c}\text { Period } 1 \\
(\mathrm{k}=1)\end{array}$ & $\begin{array}{c}\text { Period } 2 \\
(\mathrm{k}=2)\end{array}$ \\
\hline Sequence AB $(\mathrm{i}=1)$ & $\mu+\pi_{1}+\tau_{\mathrm{A}}$ & $\mu+\pi_{2}+\tau_{\mathrm{B}}+\lambda_{\mathrm{A}}$ \\
\hline Sequence BA $(\mathrm{i}=2)$ & $\mu+\pi_{1}+\tau_{\mathrm{B}}$ & $\mu+\pi_{2}+\tau_{\mathrm{A}}+\lambda_{\mathrm{B}}$ \\
\hline Sequence AA $(\mathrm{i}=3)$ & $\mu+\pi_{1}+\tau_{\mathrm{A}}$ & $\mu+\pi_{2}+\tau_{\mathrm{A}}+\lambda_{\mathrm{A}}$ \\
\hline Sequence BB $(\mathrm{i}=4)$ & $\mu+\pi_{1}+\tau_{\mathrm{B}}$ & $\mu+\pi_{2}+\tau_{\mathrm{B}}+\lambda_{\mathrm{B}}$ \\
\hline
\end{tabular}

Table 2 Notes:

Sequence $\mathrm{AB}(\mathrm{i}=1)$ : $\mathrm{E}\left(\mathrm{y}_{\mathrm{AB}, 1}\right)=\mu_{\mathrm{AB}, 1}=\mu+\pi_{1}+\tau_{\mathrm{A}}, \mathrm{E}\left(\mathrm{y}_{\mathrm{AB}, 2}\right)=\mu_{\mathrm{AB}, 2}=\mu+\pi_{2}+\tau_{\mathrm{B}}+\lambda_{\mathrm{A}}$

Sequence BA (i $=2): \mathrm{E}\left(\mathrm{y}_{\mathrm{BA}, 1}\right)=\mu_{\mathrm{BA}, 1}=\mu+\pi_{1}+\tau_{\mathrm{B}}, \mathrm{E}\left(\mathrm{y}_{\mathrm{AB}, 2}\right)=\mu_{\mathrm{BA}, 2}=\mu+\pi_{2}+\tau_{\mathrm{A}}+\lambda_{\mathrm{B}}$

Sequence $\mathrm{AA}(\mathrm{i}=3)$ : $\mathrm{E}\left(\mathrm{y}_{\mathrm{BA}, 1}\right)=\mu_{\mathrm{AA}, 1}=\mu+\pi_{1}+\tau_{\mathrm{A}}, \mathrm{E}\left(\mathrm{y}_{\mathrm{AB}, 2}\right)=\mu_{\mathrm{BA}, 2}=\mu+\pi_{2}+\tau_{\mathrm{A}}+\lambda_{\mathrm{A}}$

Sequence BB (i=4): $\mathrm{E}\left(\mathrm{y}_{\mathrm{BA}, 1}\right)=\mu_{\mathrm{BA}, 1}=\mu+\pi_{1}+\tau_{\mathrm{B}}, \mathrm{E}\left(\mathrm{y}_{\mathrm{AB}, 2}\right)=\mu_{\mathrm{BA}, 2}=\mu+\pi_{2}+\tau_{\mathrm{B}}+\lambda_{\mathrm{B}}$

In sequence $A B$, the contrast $c_{1}$ has the expected value of $E\left[c_{1}\right]=E\left[y_{11}-y_{21}\right]=\left(\pi_{1}-\pi_{2}\right)+\left(\tau_{A}-\tau_{B}\right)-\lambda_{A}$

In sequence $B A$, the contrast $c_{2}$ has the expected value of $E\left[c_{2}\right]=E\left[y_{21}-y_{22}\right]=\left(\pi_{1}-\pi_{2}\right)-\left(\tau_{A}-\tau_{B}\right)-\lambda_{B}$

In sequence $A A$, the contrast $c_{3}$ has the expected value of $E\left[c_{3}\right]=E\left[y_{31}-y_{32}\right]=\left(\pi_{1}-\pi_{2}\right)-\lambda_{A}$

In sequence $B B$, the contrast $c_{4}$ has the expected value of $E\left[c_{4}\right]=E\left[y_{41}-y_{42}\right]=\left(\pi_{1}-\pi_{2}\right)-\lambda_{B}$

In sequence $A B$, the contrast $c_{5}$ has the expected value of $E\left[c_{5}\right]=E\left[y_{11}+y_{21}\right]=2 \mu+\left(\pi_{1}+\pi_{2}\right)+\left(\tau_{A}+\tau_{B}\right)+\lambda_{A}$

In sequence $\mathrm{BA}$, the contrast $\mathrm{c}_{6}$ has the expected value of $\mathrm{E}\left[\mathrm{c}_{6}\right]=\mathrm{E}\left[\mathrm{y}_{21}+\mathrm{y}_{22}\right]=2 \mu+\left(\pi_{1}+\pi_{2}\right)+\left(\tau_{\mathrm{A}}+\tau_{\mathrm{B}}\right)+\lambda_{\mathrm{B}}$

and has the expected value of $\mathrm{E}\left[\mathrm{c}_{6}\right]=\mathrm{E}\left[\mathrm{y}_{21}+\right.$ $\left.\mathrm{y}_{22}\right]=2 \mu+\left(\pi_{1}+\pi_{2}\right)+\left(\tau_{\mathrm{A}}+\tau_{\mathrm{B}}\right)+\lambda_{\mathrm{B}}$. A linear combination of $\left[1 / 2\left(c_{5}-c_{6}-c_{3}+c_{4}\right)\right]$ yields an unbiased estimate of carryover effects $\left(\lambda_{A}-\lambda_{B}\right)$.

\section{Two-Treatment, Three-Period Crossover Design}

The second design strategy is to extend the $\mathrm{AB} \mid \mathrm{BA}$ design by adding a third period and repeating one of the two treatments: This has several attractive advantages. For example, in clinical studies major costs are associated with planning and patient recruitment rather than routine follow-up, thus, an added period may not imply a large additional cost. The added treatment period will allow carryover effects to be estimated and compared with the withinsubject variability. Finally, a careful selection of the treatment sequences to be used will insure that the first two trial periods constitute a conventional two-period crossover trial if the third treatment period leads to excessive subject drop-outs.

In three period crossover trial with two treatments, six possible treatment sequences can result when two treatments are applied in three periods. Two of these sequences, $\mathrm{AAB}$ and BBA can be omitted because they do not enable carryover effects from A and B to be examined in the same subject and the first two periods do not constitute a conventional two-period crossover design.

The four remaining sequences $\mathrm{ABB}$, $\mathrm{BAA}, \mathrm{ABA}$ and $\mathrm{BAB}$ may be used in pairs to form two-treatment sequence three-period designs, three-treatment sequence three-period designs and one four-treatment sequence threeperiod design. Of the two-treatment sequence, three-period, the $\mathrm{ABB} \mid \mathrm{BAA}$ is known to be the universally optimal design within the class of three periods (Cheng \& Wu, 1980; Laska \& Meisner, 1985; Hedayat \& Stufken, 2003). In these designs half the subjects are randomly assigned to each sequence.

Two additional efficient two-treatment, three-period designs are the $\mathrm{AAB} \mid \mathrm{ABA}$ and $\mathrm{ABA} \mid \mathrm{ABB}$ designs. Another efficient twotreatment, three-period design is the $\mathrm{ABB}$ BAA $|\mathrm{ABA}| \mathrm{BAB}$ (Ebbutt, 1984). This set of designs with equal number of subjects per sequence is able to estimate all parameters in the 


\section{EXTENSION OF GRIZZLE'S CLASSIC CROSSOVER DESIGN}

traditional model and provide a good estimate of the treatment contrast (Ebbutt, 1984; Heydat \& Stufken, 2003, Liang \& Carriere, 2010).

A balanced model for the two-treatment three-period crossover trial, $\mathrm{ABB} \mid \mathrm{BAA}$, is shown in Table 3. In sequence $\mathrm{ABB}$, the contrast, $\mathrm{c}_{1}=\left(2 \mathrm{y}_{11}-\mathrm{y}_{21}-\mathrm{y}_{31}\right)$, has the expectation $1 / 4\left\{\left(2 \pi_{1}-\pi_{2}-\pi_{3}\right)+2\left(\tau_{\mathrm{A}}-\tau_{\mathrm{B}}\right)-\lambda_{\mathrm{A}}-\right.$ $\left.\lambda_{\mathrm{B}}\right\}$. In sequence BAA, the contrast $\mathrm{c}_{2}=\left(2 \mathrm{y}_{21}-\right.$ $\left.\mathrm{y}_{22}-\mathrm{y}_{32}\right)$ has the expectation $1 / 4\left\{\left(2 \pi_{1}-\pi_{2}-\pi_{3}\right)+\right.$ $\left.2\left(\tau_{\mathrm{B}}-\tau_{\mathrm{A}}\right)-\lambda_{\mathrm{A}}-\lambda_{\mathrm{B}}\right\}$. The difference between contrast $\mathrm{c}_{1}$ and $\mathrm{c}_{2}$ forms an unbiased estimator of $\tau_{\mathrm{A}}-\tau_{\mathrm{B}}$. It appears that the central problem of the $\mathrm{AB} \mid \mathrm{BA}$ has been solved by simply extending the design by one period. An unbiased estimator of any carryover effect, $\lambda_{A}-\lambda_{B}$ may also be constructed. Consider $c_{3}=\left(y_{11}-2 y_{21}+y_{31}\right)$ and $\mathrm{c}_{4}=\left(\mathrm{y}_{21}-2 \mathrm{y}_{22}+\mathrm{y}_{23}\right)$. The expected value of $\mathrm{E}$ $\left[c_{3}\right]$ is $1 / 3\left\{\left(\pi_{1}-2 \pi_{2}+\pi_{3}\right)+\left(\tau_{\mathrm{A}}-\tau_{\mathrm{B}}\right)-2 \lambda_{\mathrm{A}}+\lambda_{\mathrm{B}}\right\}$ and the expected value of $E\left[c_{4}\right]$ is $1 / 3\left\{\left(\pi_{1}-2 \pi_{2}+\right.\right.$ $\left.\left.\pi_{3}\right)+\left(\tau_{B}-\tau_{A}\right)-2 \lambda_{B}+\lambda_{A}\right\}$. The difference between $c_{3}$ and $c_{4}$ forms an unbiased estimate of $\lambda_{A}-\lambda_{B}$.

A second model for a two-treatment three-period crossover trial, $\mathrm{ABA} \mid \mathrm{BAB}$, is shown in Table 4. In sequence $A B A$, the expected value of $\mathrm{E}\left[\mathrm{c}_{1}\right]=\mathrm{E}\left[1 / 2\left(2 \mathrm{y}_{11}-\mathrm{y}_{21}-\mathrm{y}_{31}\right)\right]$ $=1 / 2\left\{\left(2 \pi_{1}-\pi_{2}-\pi_{3}\right)+\left(\tau_{A}-\tau_{B}\right)-\lambda_{A}-\lambda_{B}\right\}$. In sequence $\mathrm{BAB}$, the expected value of $\mathrm{E}\left[\mathrm{c}_{2}\right]=\mathrm{E}$ $\left[1 / 2\left(2 \mathrm{y}_{12}-\mathrm{y}_{22}-\mathrm{y}_{32}\right)\right]=1 / 2\left\{\left(2 \pi_{1}-\pi_{2}-\pi_{3}\right)-\left(\tau_{\mathrm{A}}-\right.\right.$ $\left.\left.\tau_{B}\right)-\lambda_{A}-\lambda_{B}\right\}$. The difference between the means of the two contrasts $c_{1}$ and $c_{2}$ forms an unbiased estimator of $\tau_{\mathrm{A}}-\tau_{\mathrm{B}}$. In testing for carryover effect, let $c_{3}=y_{11}+2 y_{21}+y_{31}$ in sequence ABA and the expected value of $\mathrm{E}\left[\mathrm{c}_{3}\right]=\mathrm{E}\left[\left(\mathrm{y}_{11}+2 \mathrm{y}_{21}\right.\right.$ $\left.\left.+\mathrm{y}_{31}\right)\right]=\left\{4 \mu+\left(\pi_{1}+2 \pi_{2}+\pi_{3}\right)+2\left(\tau_{\mathrm{A}}+\tau_{\mathrm{B}}\right)+\right.$ $\left.2 \lambda_{\mathrm{A}}+\lambda_{\mathrm{B}}\right\}$. In sequence BAB, define $\mathrm{c}_{4}=\mathrm{y}_{21}+$ $2 \mathrm{y}_{22}+\mathrm{y}_{23}$ with the expected value of $\mathrm{E}\left[\mathrm{c}_{4}\right]=\mathrm{E}$ $\left[\left(\mathrm{y}_{21}+\mathrm{y}_{22}-2 \mathrm{y}_{23}\right)\right]=\left\{4 \mu+\left(\pi_{1}+2 \pi_{2}+\pi_{3}\right)+2\left(\tau_{\mathrm{A}}\right.\right.$ $\left.\left.+\tau_{\mathrm{B}}\right)+2 \lambda_{\mathrm{B}}+\lambda_{\mathrm{A}}\right\}$. The difference between $\mathrm{c}_{3}$ and $c_{4}$ then forms an unbiased estimate of $\lambda_{A}-$ $\lambda_{\mathrm{B}}$.

Table 3: ABB|BAA Design

\begin{tabular}{|c|c|c|c|}
\hline Sequence & $\begin{array}{c}\text { Period 1 } \\
(\mathrm{k}=1)\end{array}$ & $\begin{array}{c}\text { Period 2 } \\
(\mathrm{k}=2)\end{array}$ & $\begin{array}{c}\text { Period 3 } \\
(\mathrm{k}=3)\end{array}$ \\
\hline ABB $(\mathrm{i}=1)$ & $\mu+\pi_{1}+\tau_{\mathrm{A}}$ & $\mu+\pi_{2}+\tau_{\mathrm{B}}+\lambda_{\mathrm{A}}$ & $\mu+\pi_{3}+\tau_{\mathrm{B}}+\lambda_{\mathrm{B}}$ \\
\hline BAA $(\mathrm{i}=2)$ & $\mu+\pi_{1}+\tau_{\mathrm{B}}$ & $\mu+\pi_{2}+\tau_{\mathrm{A}}+\lambda_{\mathrm{B}}$ & $\mu+\pi_{3}+\tau_{\mathrm{A}}+\lambda_{\mathrm{A}}$ \\
\hline
\end{tabular}

Table 3 Notes:

$\mathrm{ABB}(\mathrm{i}=1): \mathrm{E}\left(\mathrm{y}_{\mathrm{ABB}, 1}\right)=\mu+\pi_{1}+\tau_{\mathrm{A}}, \mathrm{E}\left(\mathrm{y}_{\mathrm{ABB}, 2}\right)=\mu+\pi_{2}+\tau_{\mathrm{B}}+\lambda_{\mathrm{A}}, \mathrm{E}\left(\mathrm{y}_{\mathrm{ABB}, 3}\right)=\mu+\pi_{3}+\tau_{\mathrm{B}}+\lambda_{\mathrm{B}}$ $\mathrm{BAA}(\mathrm{i}=2): \mathrm{E}\left(\mathrm{y}_{\mathrm{BAA}, 1}\right)=\mu+\pi_{1}+\tau_{\mathrm{B}}, \mathrm{E}\left(\mathrm{y}_{\mathrm{BAA}, 2}\right)=\mu+\pi_{2}+\tau_{\mathrm{A}}+\lambda_{\mathrm{B}}, \mathrm{E}\left(\mathrm{y}_{\mathrm{BAA}, 3}\right)=\mu+\pi_{3}+\tau_{\mathrm{A}}+\lambda_{\mathrm{A}}$ In sequence $A B B$, the expected value of $E\left[c_{1}\right]=E\left[1 / 4\left(2 y_{11}-y_{21}-y_{31}\right)\right]=1 / 4\left\{\left(2 \pi_{1}-\pi_{2}-\pi_{3}\right)+2\left(\tau_{A}-\tau_{B}\right)-\lambda_{A}-\right.$ $\left.\lambda_{\mathrm{B}}\right\}$

In sequence $B A A$, the expected value of $E\left[c_{2}\right]=E\left[1 / 4\left(2 y_{21}-y_{22}-y_{32}\right)\right]=1 / 4\left\{\left(2 \pi_{1}-\pi_{2}-\pi_{3}\right)+2\left(\tau_{B}-\tau_{A}\right)-\lambda_{A}\right.$ $\left.-\lambda_{\mathrm{B}}\right\}$

In sequence $A B B$, the expected value of $E\left[c_{3}\right]=E\left[1 / 3\left(y_{11}-2 y_{21}+y_{31}\right)\right]=1 / 3\left\{\left(\pi_{1}-2 \pi_{2}+\pi_{3}\right)+\left(\tau_{A}-\tau_{B}\right)-2 \lambda_{A}\right.$ $\left.+\lambda_{\mathrm{B}}\right\}$

In sequence BAA, the expected value of $E\left[c_{4}\right]=E\left[1 / 3\left(y_{21}-2 y_{22}+y_{23}\right)\right]=1 / 3\left\{\left(\pi_{1}-2 \pi_{2}+\pi_{3}\right)+\left(\tau_{B}-\tau_{A}\right)-2 \lambda_{B}\right.$ $\left.+\lambda_{\mathrm{A}}\right\}$ 
JAMES F. REED

Table 4: ABA|BAB

\begin{tabular}{|c|c|c|c|}
\hline Sequence & $\begin{array}{c}\text { Period 1 } \\
(\mathrm{k}=1)\end{array}$ & $\begin{array}{c}\text { Period 2 } \\
(\mathrm{k}=2)\end{array}$ & $\begin{array}{c}\text { Period 3 } \\
(\mathrm{k}=3)\end{array}$ \\
\hline ABA $(\mathrm{i}=1)$ & $\mu+\pi_{1}+\tau_{\mathrm{A}}$ & $\mu+\pi_{2}+\tau_{\mathrm{B}}+\lambda_{\mathrm{A}}$ & $\mu+\pi_{3}+\tau_{\mathrm{A}}+\lambda_{\mathrm{B}}$ \\
\hline $\mathrm{BAB}(\mathrm{i}=2)$ & $\mu+\pi_{1}+\tau_{\mathrm{B}}$ & $\mu+\pi_{2}+\tau_{\mathrm{A}}+\lambda_{\mathrm{B}}$ & $\mu+\pi_{3}+\tau_{\mathrm{B}}+\lambda_{\mathrm{A}}$ \\
\hline
\end{tabular}

Table 4 Notes:

$\mathrm{ABA}(\mathrm{i}=1): \mathrm{E}\left(\mathrm{y}_{\mathrm{ABB}, 1}\right)=\mu+\pi_{1}+\tau_{\mathrm{A}}, \mathrm{E}\left(\mathrm{y}_{\mathrm{ABA}, 2}\right)=\mu+\pi_{2}+\tau_{\mathrm{B}}+\lambda_{\mathrm{A}}, \mathrm{E}\left(\mathrm{y}_{\mathrm{ABA}, 3}\right)=\mu+\pi_{3}+\tau_{\mathrm{A}}+\lambda_{\mathrm{B}}$
$\mathrm{BAB}(\mathrm{i}=2): \mathrm{E}\left(\mathrm{y}_{\mathrm{BAB}, 1}\right)=\mu+\pi_{1}+\tau_{\mathrm{B}}, \mathrm{E}\left(\mathrm{y}_{\mathrm{BAB}, 2}\right)=\mu+\pi_{2}+\pi_{3}+\lambda_{\mathrm{B}}, \mathrm{E}\left(\mathrm{y}_{\mathrm{BAB}, 3}\right)=\mu+\pi_{3}+\tau_{\mathrm{B}}+\lambda_{\mathrm{A}}$
In sequence $\mathrm{ABA}, \mathrm{E}\left[\mathrm{c}_{1}\right]=\mathrm{E}\left[1 / 2\left(2 \mathrm{y}_{11}-\mathrm{y}_{21}-\mathrm{y}_{31}\right)\right]=1 / 2\left\{\left(2 \pi_{1}-\pi_{2}-\pi_{3}\right)+\left(\tau_{\mathrm{A}}-\tau_{\mathrm{B}}\right)-\lambda_{\mathrm{A}}-\lambda_{\mathrm{B}}\right\}$
In sequence $\mathrm{BAB}, \mathrm{E}\left[\mathrm{c}_{2}\right]=\mathrm{E}\left[1 / 2\left(2 \mathrm{y}_{21}-\mathrm{y}_{22}-\mathrm{y}_{32}\right)\right]=1 / 2\left\{\left(2 \pi_{1}-\pi_{2}-\pi_{3}\right)-\left(\tau_{\mathrm{A}}-\tau_{\mathrm{B}}\right)-\lambda_{\mathrm{A}}-\lambda_{\mathrm{B}}\right\}$
In sequence $\mathrm{ABA}, \mathrm{E}\left[\mathrm{c}_{3}\right]=\mathrm{E}\left[\left(\mathrm{y}_{11}+2 \mathrm{y}_{21}+\mathrm{y}_{31}\right)\right]=\left\{4 \mu+\left(\pi_{1}+2 \pi_{2}+\pi_{3}\right)+2\left(\tau_{\mathrm{A}}+\tau_{\mathrm{B}}\right)+2 \lambda_{\mathrm{A}}+\lambda_{\mathrm{B}}\right\}$
In sequence $\mathrm{BAB}, \mathrm{E}\left[\mathrm{c}_{4}\right]=\mathrm{E}\left[\left(\mathrm{y}_{21}+2 \mathrm{y}_{22}+\mathrm{y}_{32}\right)\right]=\left\{4 \mu+\left(\pi_{1}+2 \pi_{2}+\pi_{3}\right)+2\left(\tau_{\mathrm{A}}+\tau_{\mathrm{B}}\right)+2 \lambda_{\mathrm{B}}+\lambda_{\mathrm{A}}\right\}$

Discussion

Advantages of a crossover trial are that each subject is used as their own control, optimal two treatment three-period crossover designs are statistically efficient and these designs require fewer subjects for the same number of observations than do non-crossover designs. This latter advantage is an important aspect, particularly in situations where the experimental subjects are scarce and are expensive to recruit and maintain in the study. Another advantage of crossover designs is that, by a defining a specific choice of treatment sequences, it is possible to estimate important treatment contrasts even when assuming a carryover effect in the overall model.

The major concern in a crossover design is the presence of carryover effects. In any given period, an observation from a subject is affected not only by the direct effect of a treatment in the period in which it is applied, but possibly by the effect of a treatment applied in the preceding period. In a clinical study, particularly a drug study, one way to avoid the impact of a carryover effect is to insert a rest period between two successive periods with the hope that the carryover effect would wash out during this period. This is the most common method of handling effects of drug studies. The insertion of rest periods effectively increases the interval between the observed periods and may help in overcoming the carryover effect if the carryover effect is not expected to persist, however, inserting rest periods may not be feasible. The insertion of a rest period between each pair of successive periods increases the total duration of the experiment and there is no guarantee that the wash out period is sufficiently long enough to eliminate any carryover effect. An alternative is to design the experiment in such a manner that the difference in treatment effects may be estimated after adjusting for the presence of possible carryover effects.

Despite some of the problems associated with the use of a crossover design its advantages are attractive. Although crossover designs have been in use for several decades, issues relating to the finding optimal crossover designs have been addressed only in about the last 30 years. There has been a continuous effort in the general area of optimal crossover designs, often assuming different underlying models. The uniform consistency has been the inclusion of carryover effect. These models, in turn, may be regarded as an approximation to the real world relationship between the response and the effects included in the model. A caution worth noting: Any crossover design under an assumed model might not be the optimal if the model is incorrectly specified. 


\section{EXTENSION OF GRIZZLE'S CLASSIC CROSSOVER DESIGN}

\section{Conclusion}

Although there are crossover models that specify higher order carryover effects, the two-treatment three-period designs described herein maintain their optimality characteristics. To address the potential of first-order carryover effect, the classic $\mathrm{AB} \mid \mathrm{BA}$ crossover design could be extended to a three-period design using one of the designs outlined. In effect, the added treatment period permits any carryover effects to be estimated and compared with the withinsubject variability. A careful selection of the treatment sequences would reduce to a classic two-treatment, two-period conventional crossover trial if the third treatment period leads to excessive subject drop-outs.

The statistical properties of twotreatment, three-period designs is well known but seldom used. When the traditional statistical model is acknowledged as being reasonable, these designs provide a framework to estimate treatment effects even in the presence of a carryover effect and effectively provide a way to address the impasse imposed by the classic $\mathrm{AB} \mid \mathrm{BA}$ design.

\section{References}

Balaan, L. N. (1968). A two-period design with $\mathrm{t}^{2}$ experimental units. Biometrics, 24, 61-73.

Chen, L., \& Tsong, Y. (2007). Design and analysis for drug abuse potential studies: Issues and strategies for implementing a crossover design. Drug Information Journal, 41, 481-89.
Ebbutt, A. F. (1984). Three-period crossover designs for two treatments. Biometrics, 40, 219-24.

Freeman, P. R. (1989). The performance of the two-stage analysis of two-treatment, twoperiod cross-over trials. Statistics in Medicine, 8 , 1421-1432.

Grizzle, J. E. (1965). The two-period change-over design and its use in clinical trials. Biometrics, 21, 467-480.

Hedayat, A. S., \& Stufken, J. (2003). Optimal and efficient crossover designs under different assumptions about the carryover effects. Journal of Biopharmaceutical Statistics, 13, 519-28.

Laska, E., Meisner, M., \& Kushner, H. B. (1983). Optimal crossover designs in the presence of carryover effects. Biometrics, 39, 1087-91.

Liang, Y., \& Carriere, K. C. (2010). On the role of baseline measurements for crossover designs under the self and mixed carryover effects model. Biometrics, 66, 140-148.

Senn, S. J. (1994). The AB/BA crossover design, past, present and future? Statistical Methods in Medical Research, 3, 303-324.

Senn, S. J. (1996). The AB/BA crossover: how to perform the two-stage analysis if you can't be persuaded that that you shouldn't. In M. Hanses, Ed., ed. Liber Amicorum Roel van Strik, 93-100. Rotterdam, Netherlands: Erasmus University. Available at http:// www.ucl.ac.uk/ ucaksjs/roel.pdf.

Willan, A. R., \& Pater J. L. (1986). Carryover and the two-period crossover clinical trial. Biometrics, 42, 593-599. 